about 20 per cent. of epileptics, and in the majority of these there were more salient symptoms of the disorder. In four instances the epileptic attack towards its termination presented all the features of an hysterical crisis. In eight cases the epileptic and hysterical fits in the same individual occurred independently. In the majority of the other cases12-besides the stigmata pointing to hysteria were such symptoms as neuralgic pains, headaches not connected with fits, palpitation, sleeplessness, vivid dreams, tremor, and pain over the heart.

Certain of the hysterical stigmata were found in 25 out of 96 cases of Sydenham's chorea, and in many some more pronounced features of the disease were also present. Together with the incoördinate movements of chorea, there were such manifestations as rhythmical spasm of an arm, rhythmical twitching of the eyelids, regular clonic movements of the legs, and rigidity of the legs. In one case hysterical rhythmical spasm followed chorea after an interval of two days, and in another in the course of two months. In two other instances the chorea was not of the ordinary type, and seemed to be a hysterical or subconscious renewal of former attacks of genuine chorea. In the remainder of the 25 cases there were such symptoms as neuralgic pains and tender spots in 10, vomiting without apparent cause in 2 , aphonia in 2, semi-hysterical attacks in 4, typical hysterical cough in 1 . To emphasise the distinction between ordinary and the so-called hysterical chorea several tracings were exhibited of rhythmical tremor and spasm.

The infective diseases, continued Professor Glynn, may provoke hysteria, and the affection may complicate their progress as well as follow during convalescence. Cases of rheumatic fever and typhoid associated with hysteria were referred to. Chlorosis for obvious reasons was, he said, very frequently attended with hysteria. Out of 164 cases of chlorosis, 45 , or 25 per cent., were hysterical. In 20 out of the 45 there was much headache, as a rule vertical, with restlessness at night and vivid dreaming. Eighteen suffered more or less from obstinate vomiting and gastralgia, 5 had hysterical fits in some form, 8 exhibited fine tremor of the hands, 4 complained of pain and tenderness over some part of the spine, and 3 of great weakness of the legs. Two developed hysterical anorexia.

In Graves's disease the hysterical stigmata were present in 35 per cent.

There was evidence of hysteria in the presence of the stigmata and in a few of other symptoms, in threefourths of the cases of simple gastralgia in young women. It was not likely that the hysteria was only accidentally associated with the gastralgia, since they were found together in so many instances ; moreover, the hyperæsthesias and pains are just as characteristic a feature of hysteria as are the anæsthesias.

$\mathrm{He}$ had met with 15 cases of anorexia nervosa, and in each of these certain hysterical stigmata were present. One subject of the disease became comatose and was measured for her coffin, but uı dər vigorous treatment recovered. Two died, one was removed to a nursing home when hopelessly weak and the other recovered for a while but in 12 months relapsed and died. Another case was very exceptional, the subject of the disorder being a boy.

The hysterical stigmata were present in 23 per cent. of the cases of gastric ulcer in young women, that is in patients with a history of hæmatemesis or melæna.

The relation of hysteria to heart disease was of special interest. Such hysterical affections as pseudo-angina, or simple piin over the heart, palpitation, dyspnca, and syncope, when the heart is normal arouse fears of cardiac disease in the patient, and worrs the medical attendant till he lights on the explanation of the symptoms, and when these hysterical accidents occur in casts where there are signs of organic $\mathrm{h}+$ art disease they are likely to cause the patient's condition to appear more serious than it is. Further, as nervousness, sleeplessness, and pain are usually associatien with hysteria the symptoms due to heart disease tend to be aggravated. Several cases were referred to in illustration. One was a girl with mitral stenosis who after a faint lost the power of her left arm; the paralysis proved to be hysterical in nature and not due to cerebral embolism.

In conclusion, Professor Glynn discussed the alliance between hysteria and the functional and organic diseases of the nervous system.

\section{ON THE STATE OF THE BLOOD-VESSELS IN SHOCK.}

Bx JOHN D. MALCOLM, F.R.C.S. Forn., SENIOR SURGEON TO THE SAMARITAN FREE HOSPITAL, LONDON.

IN $1893 \mathrm{I}$ published ${ }^{1}$ my belief that in cases of fever, of post-operative intestinal obstruction, and of traumatic shock there is a contraction of the arteries extending from the arterioles to the larger vessels and progressing until the causal conditions are removed or the patient is moribund. That view was opposed to the teaching of the day that the vessels of the splanchnic area become paralysed in the state of shock and it has also been urged from time to time ${ }^{2}$ against the theory that the vessels throughout the body become relaxed. This last theory has for the past six or eight years been almost universally accepted, but recently its accuracy has been less assured, and at the Seventeenth International Congress of Medicine, in the debate on the Pathology of Shock, ${ }^{3}$ not one speaker suggested that the arteries are relaxed or dilated in that condition.

The time, therefore, seems opportune for a review of the evidence on this subject, and I propose to state again very shortly the chief points in the argument in favcur of the contention that the arteries contract as shock develops, and to indicate some of the more recent facts which have been brought forward in relation to this question. I give precedence to the clinical evidence because it constitutes my justification for offering an opinion and because the value of laboratory work to the surgeon must in the long run be judged by its success in explaining clinical conditions.

\section{Clinical Considerations.}

When in the course of an operation a patient passes into the state of shock, even if he loses little or no blood directly from divided structures, his tissues become obviously more and more bloodless, and careful observation during operations upon the abdomen shows that the anæmia is as conspicuous in the splanchnic area as in any other. This observation has been confirmed by Dr. G. W. Crile who wrote concerning his laboratory work that both before and after death from shock " the arteries were quite empty, the tissues pale." He also said that when the splanchnic area was not involved in the manipulations of an experiment " autopsies did not reveal a condition of vascular distension in this area different from that of other areas." ${ }^{\circ}$ Unless these observations are altogether mistaken, it is certain that there is no dilatation of the vessels generally or of those in the splanchnic area alone in the state of shock.

During the progress of severe operations it may occasionally be observed that the arteries become imperceptible at the wrist whilst the pulse-rate is not quickened or even is slower, and the beats of the carotid are full and $b$ tunding. On one occasion it was noted that at the end of an operation upon a healthy young woman the pulse-rate was 48 to the minute, and no pulsation was perceptible in any vessel of the extremities. The operation, an ovariotomy. was not a severe one, and the usual state of the ressels was restored after a very short time. A similar combination of signs was frequently observed passing gradually back to the normal or developing into the rapid heart action which is characteristic of well-marked cases of shock.

Such conditions could only arise from an increased opposition to the flow of blood through the small vessels and a well-sustained output of blood from the heart. The dissociation for a time of the small, weak, or imperceptible pulse from the hastening of the heart beats which usually accompanies it suggested that the arterial contraction was the more constant change. It did not seem pos-ible that in some cases the arteries could be contracted whilst in others they were relaxed, or that in the particular cases now under discussion the active contraction which certainly

The Physiology of Death from Traumatic Fever. J. and A. Ohurchill ; also THE LANCET, Feb. 25th (p. 408) and March 4th (p. 460),

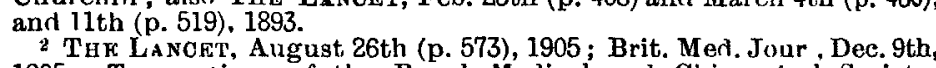
1905; Transactions of the Royal Medical and Chiruryiled Soriety, 19n5; Transactions of the Royal Medical and Chiruruilen Soliety,
vol. xc., p. 563 ; Transactions of the Medical Society of Loudun, 1909 . voction II X., General Pathology and Pathological Anatomy.

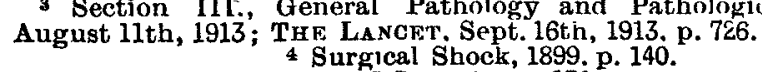


occurred could become a relaxation without some sign of the gradual or sudden change. If the change was gradual the pulse at the wrist would come back to its ordinary volume if only for a short time, a condition never observed during the development of shock. If contraction of the vessels suddenly became relaxation there would certainly be some acute disturbance which could not be overlooked clinically. As there were no signs of any such changes, there could be no doubt that the contracted ressels did not relax.

All authorities agree that the heart is stimulated to greater effort as shock develops and there seemed to me to be much reason for believing that the slow heart action associated with a small or imperceptible peripheral pulse might be observed more readily, if not only, in cases in which the heart muscle was relatively strong. When these observations were made the work at the Samaritan Free Hospital consisted in great part of the removal of large ovarian tumours, and it seems probable that such cases offered unusual opportunities for the observation of the effects of a comparatively powerful heart. It is well known that cardiac hypertrophy is a physiological effect of gestation, and it is reasonable to suppose that the presence of an ovarian tumour would at least occasionally induce a similar change. This view was supported by the fact that in a few cases an opportunity was obtained of examining the heart at a necropsy when its action had for a time remained slow after the pulse at the wrist became very small or imperceptible, and in these cases the cardiac muscle was always well developed, whilst in one instance there was a very obvious cardiac hypertrophy without any gross cardiac or renal lesion or other discovered cause of this condition except the presence of the tumour. The facts recorded led me to assert in 1893 that "if the heart be sufficiently strong its action remains slow," 6 but that if still greater contraction of the vessels takes place the heart becomes relatively feeble and its pace quickens.

The extreme pallor in all the tissues, the definite evidence that in some cases the arteries were tensely contracted whilst the heart action was not hastened, the known fact that stimulation of the sensory nerves causes arterial contraction, and many other observations which cannot be set down in a short paper, were considered together to form a proof that "in traumatic fever, in shock and in abdominal distension following a laparotomy, the small feeble pulse, whether slow or fast, is in no sense due to cardiac weakness, is not a condition beginning at the heart, but is an immediate effect of the contraction of the vessels." 7

If these contentions were true it was certain that the total volume of blood in the arteries must diminish, and in the absence of any marked verous distension it was argued that the fluid parts of the blood must escape from the vessels into the tissues. In cases of intestinal obstruction after abdo- minal operations, in which also it was held that the vascular capacity steadily diminished, there was no doubt that a great loss of fluid from the body did occur, because this condition is characterised by an extreme degree of exudation of fluid into the intestine and out of the body by vomiting. Moreover, in this condition the vomited fluid is at first clear, and gradually becomes yellow, green, brown, and nearly black. These changes indicate that not only fluid escapes from the vessels but that there is also an excessive and increasing destruction of blood cells in the liver. In the state of shock there is little time for such obvious indications of blood destruction to show themselves, and it does not follow that an excessive secretion of bile of short duration will be ejected from the stomach through the cesophagus, but sometimes recovery from shock is accompanied by vomiting of bilious or even black fluid, and the amount of fluid lost from the skin is always great when the condition is well marked.

The loss of fluid and other constituents of the blood from the vessels was regarded as the cause of the extreme anæmia of the whole body, and death was attributed to a starvation of the various tissues and organs which might be traced in the evidences of the failure of their functions. When the vaso-motor centres were affected the whole body died.

\section{Experimental Considerations.}

A short résumé of the experimental evidence shows that it is conclusive in support of the clinical. The theory that in

6 The Physiology of Death from Traumatic Fever, p. 67. Physiologi al teaching was quoted in support of this view,

$$
\text { t Loc. cit., p. } 66 \text {. }
$$

shock the animal bleeds into its own splanchnic veins has now no supporters. Dr, G. W. Crile's first book advocating the view that shock is characterised by a general vascular relaxation was published in $1899,{ }^{\circ}$ and in that year also Romberg and Pässler ${ }^{9}$ advanced the same view on very much the same grounds with regard to the conditions found in toxæmic fevers. In regard to both shock and toxæmic fevers it was argued that death was not due to cardiac failure, as was then generally believed, but that there arose a loss of tone in the vaso-motor system followed by a failure of the circulation when the vessels relaxed. This view had a great vogue as regards shock until quite recently. Romberg and Pässler's communication did not apparently attract so much attention.

The argument depended entirely upon the interpretation of the fall of blood pressure. It has long been known that a stimulation of sensory nerves excites reflexly a general arterial contraction and a consequent rise of blood pressure in the large arteries. Conversely a relaxation of the vessels lowers blood pressure in the large arteries. It was shown in 1899 that if the stimulations of tissue were sufficiently severe or if fever was sufficiently continuous the blood pressure after a rise fell very low, and this was regarded as a proof that arterial relaxation had occurred. It was argued that the fall of the pressure became so great that when the state of shock was fully established the vessels were completely relaxed, and this condition was attributed to a paralysis of the vaso-motor centres from over-stimulation and consequent exhaustion of their energy. But this argument omitted altogether the possibility that the volume of blood in the vascular system might diminish and the obvious fact that the tissues became anæmic both in shock and in fever. As Yandell Henderson has pointed out, the conclusion that the vessels relaxed was arrived at because the authors of this view "applied to their problem that conception of the circulation which the physiology of to-day teaches. This was their sole mistake." 10 Many new facts were demonstrated by detailed records of most interesting experimental work, and none of these facts have been contradicted in any material respect, but the evidence is now very strong that the interpretation was at fault. As early as 1903 physiologists began to question the evidence that the vaso-motor centres become paralysed. In that year Professor W. T. Porter and Dr. W. C. Quinby, of the Harvard Medical School, published experiments showing that in the state of shock the vessels were still influenced reflexly by nerve stimulations, and they concluded that "exhaustion of the vaso-constrictor nerves cannot therefore be the essential cause of the symptoms termed "shock." "1i

In 1907 Professor Porter recorded another "investigation into the effect of uniform stimulations of the depressor brachial and sciatic nerves at various levels of blood pressure from the normal down to about $9 \mathrm{~mm} . " 12$ of mercury. He showed that "the absolute change in blood pressure upon stimulating these afferent nerves remains almost unchanged until the blood pressure has fallen to about one-third its usual height,'s and that "the reflex fails only when the blood pressure sinks to a level at which anæmia of the vasomotor centres is certain. Indeed, all we know regarding these and similar cells strengthens the belief that their endurance under stimulation is very great. On the other hand, they are extraordinarily sensitive to changes in the blood-supply." It was added that "the data presented are wholiy oppesed to the hypothesis that 'would explain surgical shock by the exhaustion of the vaso-motor centres." 14

The question of the state of the vessels in shock was also studied by Dr. M. G. Seelig and Professor E. P. Lyon, of Saint Louis, Mo., U.S.A. ${ }^{15}$ who performed an ingenious experiment upon a series of dogs showing that division of the sciatic nerve made a greater proportional increase of the blood flow from the previously divided femoral vein in a shocked animal than the increase observed in the other leg of the same animal before the state of shock was brought about. The deduction was drawn that " this proportional difference must

8 Surgical Shock, Boston, 1899

9 Deutsches Archiv für Clinische Medicin, 1899, vol. lxiv., p. 652 10 American Journal of Physiology, vol. xxvii., p. 154 .
(5)

11 Boston Medical Journal. 1903, pp. 455-56; American Journal of Physiology, 1903-1904, xii., xiii.

$$
\begin{aligned}
& 12 \text { American Journal of Physiology, 1907, xx., p. } 399 \\
& 13 \text { Loc. cit., p. 404-05 }
\end{aligned}
$$

15 Jonrnal of American Medical Association, Jan. 2nd, 1909, vol, lii., pp. $45-48$. 
be referred to the fact that in the shocked animal, before division of the sciatic the vessels are in a state of greater contraction than they are in the normal animal." The authors of these observations invited Dr. John Green, jun., to examine the eyes of dogs before and after the induction of shock, and to note carefully the size of the vessels of the fundus without telling him what was or was not expected "In every instance he reported that the vessels showed a marked degree of contraction after the animal was in shock." Sometimes the vessels resembled mere threads, and in one case the contraction was observed immediately before the animal died.

Dr. Eugene Boise holds that the chief cause of the fall of blood pressure in shock is an abnormal increase in cardiac contraction and a decrease of cardiac relaxation by which the capacity of the heart becomes so reduced that it cannot adequately fulfil its propelling functions. From an analysis of Crile's records and from his own investigations Boise argued that in shock "there is an excessive irritation of both the vascular and cardiac centres whereby the arteries and heart are both almost spasmodically contrasted." 16

Professor Yandell Henderson, of Yale University, U.S.A., has formulated a very large conception regarding the effects of diminution of the quantity of $\mathrm{CO}_{2}$ in the tissues. His views are in many respects altogether original, and they seem to me to throw a flood of light upon conditions about which we have hitherto been quite in the dark. Haldane and Priestley had confirmed ${ }^{17}$ the observation of Miescher that variations in the amount of $\mathrm{CO}_{2}$ in the body are very important and had shown that very slight differences of the pressure of this gas in the pulmonary alveoli (normally about 5.5 per cent. of an atmosphere) lead to an immediate hastening or slowing of the respiration until the normal tension is readjusted.

Mosso had demonstrated 18 that under reduced atmo. spheric pressure the $\mathrm{CO}_{2}$ content of the blood is diminished and that this diminution is one of the causes of the disturbance of function in mountain sickness. He suggested the term acapnia ( $a$, privative, and $\kappa a \pi \nu b s$, smoke) for this diminished pressure of $\mathrm{CO}_{2}$.

Following up these indications Henderson worked out his scheme and he has summarised his views thus. ${ }^{19}$

From the data to be presented in this series ${ }^{20}$ of papers it appears that the $\mathrm{CO}_{2}$ content of the blood exercises regulating influences upon the heart rate, upon vascular tonus, upon the peristalsis of the alimentary canal, upon the mental condition and upon a number of other functions of the body to a degree so far as we can find from the literature, hitherto in great part not demonstrated. These data show that even a slight reduction in the $\mathrm{CO}_{2}$ content of the arterial blood causes a marked quickening of the heart rate. Further reduction induces an extreme tachycardia, complete cessation of peristalsis, failure of many reflexes and coma. If an extreme reduction of the fallure of many reflexes and coma. If an extreme reduction of the $\mathrm{CO}_{2}$ content of the blood is effected very rapidly the heart comes into a state bordering on tetanus. This cardiac tetanus practically abolishes the pumping action of the heart, arterial pressure falls therefore, and ath results.

If the reduction in the arterial $\mathrm{CO}_{2}$ is less extreme, but is maintained for a considerable time (an hour or more according to the extent of the reduction), so that the tension of $\mathrm{CO}_{2}$ in the venous blood and in the tissues is greatly reduced, symptoms and conditions result which are similar in many respects to those occurring in mountain sickness and apparently identical with those of shock.

Henderson says that "acute acapnia diminishes the volume of the blood as effectively as does an extensive hæmorrhage," ${ }_{21}$ and that "arterial pressure ultimately sinks in spite of an intense activity (not because of failure) in the vaso-motor nervous system, and in spite of an extreme constriction (not because of relaxation) of the arterioles." ${ }^{22}$

The influence of a subnormal amount of $\mathrm{CO}_{2}$ in the tissues has been investigated also by Dr. E. Jerusalem and Professor E. H. Starling of University College, London, who state that their experiments ${ }^{23}$ confirm Yandell Henderson "in his description of the action of the heart when the $\mathrm{CO}_{2}$ of the blood is reduced to very low limits."

Thus from many independent sources there is an overwhelming mass of experimental evidence, and much more could be quoted, to the effect that the heart and the vessels

16 The Nature of Shock, American Journal of Obstetrics, vol. lv., No. 1 .

$$
17 \text { The Journal of Physiolngy, 1905, vol. xxxii., p. } 225 .
$$

18 Mosso and Marro: Archives Italiennes de Biologie, 1903, vol. xxxix., po. 387, 395, and 402; also 1904, vol. xli., p. 357. quoted by Yande

Henderson. American Journal of Physiology, 1908, vol. xxi., p. 136 19 American Journal of Physiology, 1908, vol. xxi., p. 128. 2t American Journal of Physiology, vol. xxvii., p. 161 . 22 Loc pitsiology.

23 Journal of Physiology, 1910, vol, xl., p. 284. are both stimulated to increased activity as the state of traumatic shock develops.

But Yandell Henderson's scheme involves a much wider area than the vascular changes in shock. He says that acapnia has been found "in many forms of fever, in diabetic coma, in the conditions consequent on violent muscular exercise, and in that form of shock which results from the intravenous injection of albumose and 'peptone.' In all of these conditions, as well as in mountain sickness, excessive artificial respiration, and surgical shock, there occur at one stage or another, and in varying order, hyperpnce followed by shallow respiration or apnca, tachycardia, venous congestion, and fall of arterial pressure, muscular weakness, suppression of reflexes, disturbances of consciousness and disturbances of the motor functions of the alimentary canal.", 24

It is impossible in a short paper to attempt to give any adequate account of Yandell Henderson's teaching, but it seems to be in complete accord with my contention mentioned at the beginning of this paper, that in cases of fever, of post-operative intestinal obstruction, and of traumatic shock there is a persistent and increasing contraction of the arteries, a conclusion which I believe to be demonstrable at the bedside.

These very short remarks indicate with as little detail as possible the views of the state of the vessels in shock which seem to me to be supported by the clinical and experimental facts set forth. The matter is obviously of great importance, for if it is a mistake to believe that the vessels relax as a consequence of severe or continuous injuries it is hardly likely that much real progress can be made in the study of operative conditions until that mistake is rectified. The opposite view that the vessels contract offers a much more certain guide both for understanding and treating the conditions found. And as regards the detail that in fevers and in shock the same vascular changes take place, I am convinced that this fact, as I believe it to be, gives an immense advantage in understanding clinical phenomena to those who accept it.

Wimpole-street, W.

\section{FOURTH REPORT ON TYPHOID CARRIERS.}

BY D. S. DAYIES, M.D. LOND., LL.D., D.P.H., MEDICAL OFFICER OF HEALTH OF BRISTOL; AND

I. W A L K ER H A L L, M.D. VICl.,

PROTFSSOR OF PATHOLOGY, BRISTOL UNIVERSITY, AND PATHOLOGIST TO THE BRISTOL ROYAL INFIRMARY.

With the Assistance of G. ScotT Williamson, L.R.C.P. \& S. Edin., L.F.P.S. Glasg., Pathologist to the Bristol General Hospital; and B. A. I. PETERS, B.A., M.D., D.P.H. Cantab., Resident Medical Officer, Ham Green Hospital, Bristol.

In the last report ${ }^{1}$ it was concluded that the results. then obtained justified a prolonged study of the case in hand. The present note deals with the further course of the condition.

The methods employed are the same as were detailed in former communications. For reasons previously stated the examinations have been limited to the search for typhoid bacilli in the excreta, the determination of the agglutinin contents of the serum, and the action of therapeutic agents.

The carrier was a female, aged 33, who had enteric fever in July, 1905. Since that date eight cases of infection had been traced to her. She came under observation in January, 1909, and proved to be a urinary carrier. For a period of three months urotropine was given continuously. The excretion of typhoid organisms in the urine was decreased but not inhibited entirely. On April 21st, 1909, a bacillary emulsion prepared from the patient's own organism was given. The doses were continued until 1000 millions were reached. The injections were discontinued on Sept. 29th

$$
24 \text { American Journal of Physiology, vol. xxi., p. } 141 .
$$

1 The Lancet, Sept. 3rd, 1910. See also Journal of Pathology and Bacteriology, 1910, vol. xv., p. 120 ; THE LANCET, 1908, vol. î., p. 1585 and Proceedings of the Royal Society of Medicine, 1908, Epidemiological Section, p. 175. 